\title{
1 Molecular prey identification in wild Octopus vulgaris paralarvae
}

2 Álvaro Roura ${ }^{1 *}$, Ángel F. González ${ }^{1}$, Kevin Redd $^{2}$, Ángel Guerra ${ }^{1}$

3

$4{ }^{1}$ Álvaro Roura, Ángel F. González, and Ángel Guerra. Instituto de Investigaciones Marinas (CSIC), 536208 Vigo, Spain TEL: (+34) 986231 930. FAX: (+34) 986292762

$6{ }^{2}$ Kevin Redd, Institute for Marine and Antarctic Studies (IMAS). Marine Research Laboratories, 7 University of Tasmania, Hobart, Tas, Australia. 7001

$8 \quad *$ Corresponding author: aroura@iim.csic.es

\section{Abstract}

11 The trophic ecology of Octopus vulgaris paralarvae collected in 2008 off the Ría de Vigo, NW Spain $12\left(42^{\circ} 12.80^{\prime} \mathrm{N}-9^{\circ} 00.00^{\prime} \mathrm{W}\right)$ was approached by both morphological and molecular methods. External 13 digestion of prey and posterior suction of the liquefied contents by wild $O$. vulgaris paralarvae made the 14 morphological identification of gut contents impossible. Thus, a PCR-based method using group specific 15 primers was selected to identify prey consumed by $O$. vulgaris paralarvae in the pelagic realm. The 16 mitochondrial ribosomal $16 \mathrm{~S}$ gene region was chosen for designing group specific primers, which 17 targeted a broad range of crustaceans and fishes but avoided the amplification of predator DNA. These 18 primers successfully amplified DNA of prey by using a semi-nested PCR-based approach and posterior cloning. Homology search and phylogenetic analysis were then conducted with the 20 different operational taxonomic units (OTUs) obtained to identify the putative organisms ingested. The phylogenetic analysis clustered ingested prey into 12 families of crustaceans (11 belonging to the order Decapoda and 1 to the order Euphausiacea) and two families of fishes (Gobiidae and Carangidae). According to the Czekanowski's Index (CI), the trophic niche breadth of $O$. vulgaris paralarvae is low

$24(\mathrm{CI}=0.13)$, which means that these paralarvae are specialist predators at least during the first weeks of their life cycle. It is the first time that natural prey has been identified in $O$. vulgaris paralarvae collected from the wild and such knowledge may be critical to increasing the survival of $O$. vulgaris hatchlings in captivity, a goal that has been actively pursued since the 1960's by aquaculture researchers.

28 Key words: Octopus vulgaris, paralarval diet, group specific primers, gut content, PCR, trophic ecology, 29 aquaculture.

\section{Introduction}


31 Dietary analysis in cephalopods is hampered by problems arising from the anatomy, physiology and mode of ingestion (Rodhouse and Nigmatullin 1996) of these organisms. The oesophagus diameter is limited physically as it passes through the brain, so the cephalopod beak bites small pieces of tissue to swallow. Rapid digestion rates in the stomach result in short residence times (two to six hours) making the prey remains visually unidentifiable (Altman and Nixon 1970; Andrews and Tansey 1983; Nixon 1985). The mode of prey ingestion can be internal, by biting with the beak, or external, where salivary enzymes paralyse and digest the flesh followed by the ingestion of the liquefied content (Nixon 1984; Guerra and Nixon 1987). These specialised feeding strategies largely avoid the ingestion of hard skeletal material and tend to bias data on both prey species and size when morphological analysis are used (Nixon 1985). Cephalopods are known to be highly versatile predators with opportunistic predation behaviours (reviewed in Rodhouse and Nigmatullin 1996). While numerous works have focused on the trophic role of adults (Nixon 1987; Boyle et al. 1996; Rasero et al. 1996; Rodhouse and Nigmatullin 1996), the knowledge of diet in wild paralarvae is scarce due to the small size of this life history stage. The few attempts made to clarify the diet showed that paralarvae are mainly generalist feeders preying primarily on crustaceans, as observed by visual analysis by Passarella and Hopkins (1991) and Vecchione (1991). Further visual analysis made by Vidal and Haimovici (1998) showed that $11.4 \%$ of ommastrephid squid paralarvae contained copepod appendages. Additionally, Venter et al. (1999) developed an inmunoassay that detected copepods, euphausiaciids and polichaetes in the gut of six Loligo reynaudii paralarvae.

While some squid and cuttlefish paralarvae preying on pelagic crustaceans ingest exoskeleton pieces, thus allowing morphological analysis (Vecchione 1991; Passarella and Hopkins 1991; Vidal and Haimovici 1998); the external digestion exhibited in octopod paralarvae hatchlings rejects the entire crustacean zoeae exoskeleton therefore preventing morphological analysis of the dietary items (Hernández-García et al. 2000). Occasionally, the presence of thoracic appendages has been observed in the stomach of Octopus vulgaris hatchlings fed on Artemia under laboratory conditions, because Artemia has a thinner exoskeleton than other crustacean zoeae (Iglesias et al. 2006). Octopus vulgaris is a generalist predator as both a juvenile and an adult, feeding upon a variety of organisms mainly within the class Crustacea, but also Gastropoda, Lamellibranchiata, Osteichthyes, Ophiuroidea, Polychaeta and Cephalopoda (Nigmatullin and Ostapenko 1976; Guerra 1978; Smale and Buchan 1981; Nixon 1987; Mather 1991). The industrial rearing of this octopus species has been

60 hampered by the high mortality during the pelagic stage, despite the broad range of experimental diets 
assayed throughout the past sixty years (reviewed in Iglesias et al. 2007). Although some authors have hypothesised that $O$. vulgaris prey upon crustaceans during the planktonic stage (Mangold and Boletzky 1973; Nixon 1985; Rodhouse and Nigmatullin 1996; Villanueva and Norman 2008), the feeding habits of wild $O$. vulgaris paralarvae are still unknown.

The trophic ecology of Octopus vulgaris paralarvae was tackled using both morphological and molecular methods, which have been shown to provide a comprehensive understanding of both invertebrate and vertebrate diets (Casper et al. 2007; Deagle et al. 2007, 2010; Braley et al. 2010). Given that Artemia was successfully detected in a single $O$. vulgaris paralarvae reared in laboratory by using species specific primers (Roura et al. 2010), the next step involved developing a molecular technique to detect the natural prey of wild paralarvae. This approach requires a priori knowledge of the fauna that coexist with paralarvae in the zooplankton. Hence, ten surveys were undertaken in the Ría de Vigo, a region of coastal upwelling off NW Spain (Otero et al. 2009), to obtain wild paralarvae as well as relative abundances of the different zooplankton species present in the area. Due to the enormous variety of suitable prey species in the zooplankton community; neither the species specific primer approach (King et al. 2008) nor the serological methods (Boyle et al. 1986, Venter et al. 1999) would be practical to identify prey. Therefore, we developed a technique to amplify small, multi-copy DNA fragments with universal primers for the 16S rRNA gene (Simon et al. 1994) in conjunction with group specific primers, designed within this gene, that anneal to short target templates of potential prey items (Deagle et al. 2005, 2007, 2009, 2010; Braley et al. 2010). The group specific primers were designed to amplify a wide range of crustaceans and fishes, likely the most suitable prey of wild $O$. vulgaris paralarvae, based upon reports that the feeding habits of cephalopods shift from crustacean feeders during early stages (Vecchione 1991; Vidal and Haimovici 1998; Venter et al. 1999) towards piscivory in juvenile and adult stages (Passarella and Hopkins 1991; Rasero et al. 1996).

84 The aim of this work was to identify natural prey of Octopus vulgaris paralarvae collected in the wild, using both morphological and molecular methods. Additionally, trophic selectivity of the paralarvae was addressed by comparing the composition of the zooplankton community they inhabit with the prey detected, under the assumption that cephalopod paralarvae are generalist predators. This molecular method is also immediately transferable to other oceanographic predator/prey scenarios as well as to other dietary studies on cephalopod paralarvae. 
92 Sample collection, morphologic analysis and DNA extraction

93 Ten surveys to collect zooplankton and hydrographical data were undertaken at night during July and 94 September-October 2008 in the Ría de Vigo, NW Spain $\left(42^{\circ} 12.80^{`} \mathrm{~N}-09^{\circ} 00.00^{\prime} \mathrm{W}\right)$ onboard RV 95 "Mytilus". Biological sampling consisted of four transects as in González et al. (2005); three located 96 outside the Cies Islands and one inside the Ría de Vigo (T2, T3, T4 and T5) parallel to the coast 97 following an onshore-offshore depth gradient with an average depth of 26, 68, 85 and 110m, respectively. 98 On each transect two double oblique trawls were deployed, one at the surface and one near the bottom, 99 using a $75-\mathrm{cm}$ diameter bongo net equipped with $375-\mu \mathrm{m}$ mesh and a current meter. Zooplankton samples 100 were fixed onboard with $96 \%$ ethanol and stored at $-20^{\circ} \mathrm{C}$. In the laboratory, cephalopod paralarvae were 101 separated and classified according to Sweeney et al. (1992) and our own reference collections. 102 Zooplankton composition and abundance was estimated by Roura et al. (unpublished).

103 Morphological analyses of the gut contents were carried out from two batches of eighteen randomly 104 selected Octopus vulgaris paralarvae, following two different procedures. In the first batch, the digestive 105 tracts were removed and gut contents were distributed in water on a microscope slide and then examined 106 under an inverted microscope at 100x to 400x magnification (Nikon Eclipse TS100) as in Passarella and 107 Hopkins (1991). The second batch was prepared for routine histological analysis by staining with 108 haematoxylin-eosin and examined under a microscope at 100x to 400x magnification (Nikon Eclipse 80i).

109 Genetic analysis was carried out with eighteen $O$. vulgaris paralarvae randomly sorted that were 110 preserved in $70 \%$ ethanol at $-20^{\circ} \mathrm{C}$. To avoid potential contaminants from the body surface before DNA 111 extraction, individual paralarvae were washed with sterile distilled water, which was recovered and used 112 as a negative control (Suzuki et al. 2006). Paralarvae were then dissected and their digestive system was 113 removed and placed into DNA-free tubes. All dissections were performed in a UV-sterilized laminar flow 114 hood with flame-sterilized dissection tools to avoid contamination. Gut and content DNA was extracted 115 with a QIAamp DNA Micro Kit (QIAGEN), using RNA carrier in buffer AL. All steps followed 116 manufacturer's instructions, with the exception of the $56^{\circ} \mathrm{C}$ digestion step which was done overnight and 117 the final elution step was done in two steps using $15 \mu \mathrm{l}$ buffer $\mathrm{AE}$ in each elution.

\section{Group specific primer design}

119 Group specific primers were designed by obtaining 16S rRNA sequences from GenBank (Benson et al. 120 2002) corresponding to 30 taxonomically diverse crustaceans, 3 fishes, 2 echinoderms and 2 cephalopods 
121 (one of them Octopus vulgaris) which are known to be present in the NE Atlantic Ocean (Table 5, 122 supplementary material). These sequences were then aligned with MAFFT (Katoh et al. 2002). The 123 software AMPLICON (Jarman 2004) was used to identify conserved regions within the target group of 124 potential prey species, but with nucleotide mismatches at the 3' end of the O. vulgaris forward primer 125 sequence to prevent its amplification (Deagle et al. 2007). Group specific primer specificity was tested by 126 PCR using a gradient between $49^{\circ} \mathrm{C}$ and $60^{\circ} \mathrm{C}$ on known template DNA from across the Crustacea (the

127 euphausiacid Nyctiphanes couchii, the crab Necora puber, the squat lobster Galathea strigosa, the hermit 128 crab Anapagurus laevis, the prawn Palaemon longirostris, the mysid Leptomysis gracilis and the copepod

129 Calanus helgolandicus), Chaetognata (Sagitta elegans) and O. vulgaris.

130 Genetic database of planktonic organisms from the Ría de Vigo

131 To ensure the correct identification of sequences obtained from the gut of Octopus vulgaris paralarvae, 132 mtDNA16S sequences were obtained from 25 species of crustaceans collected in the zooplankton 133 sampling done in the Ría de Vigo (Table 2). One individual of each species was visually identified, 134 washed with distilled water to remove surface contaminants and DNA was extracted with the QIAamp 135 DNA Micro Kit (QIAGEN), eluting the DNA in ultrapure water.

136 Due to difficulties amplifying crustacean 16S rRNA, PCR products were generated with different 137 combinations of the universal primers 16Sar-16Sbr (Simon et al. 1994) and the designed group specific 138 primers 16Scruf-16Scrur (Table 2). Copepod specific primers 16Sca and 16Scb (Braga et al. 1999) were 139 needed to amplify a region that is nested in the 16S rRNA universal fragment and encompasses the 140 sequence amplified with the designed group specific primers. Cycling conditions for the primers 16Sar141 16Scrur and $16 \mathrm{Scruf}-16 \mathrm{Sbr}$, consisted of an initial denaturation at $94^{\circ} \mathrm{C}$ for $2 \mathrm{~min}$ followed by 39 cycles 142 of: denaturation at $94^{\circ} \mathrm{C}$ for $30 \mathrm{~s}$, annealing at $57^{\circ} \mathrm{C}$ for $35 \mathrm{~s}$, extension at $72^{\circ} \mathrm{C}$ for $40 \mathrm{~s}$ and a final step of $1437 \mathrm{~min}$ at $72^{\circ} \mathrm{C}$. Cycling conditions for copepod primers $16 \mathrm{Sca}-16 \mathrm{Scb}$ consisted of an initial denaturation 144 at $94^{\circ} \mathrm{C}$ for 2 min followed by 38 cycles of: denaturation at $94^{\circ} \mathrm{C}$ for $60 \mathrm{~s}$, annealing at $50^{\circ} \mathrm{C}$ for $60 \mathrm{~s}$, 145 extension at $72^{\circ} \mathrm{C}$ for $60 \mathrm{~s}$ and a final step of $7 \mathrm{~min}$ at $72^{\circ} \mathrm{C}$.

146 All reactions were carried out in $25 \mu \mathrm{L}$, containing 10-100 ng of template $2.5 \mu \mathrm{L} 10 \mathrm{X}$ PCR reaction 147 buffer, $0.5 \mu \mathrm{L}$ dNTPs, $0.75 \mu \mathrm{L}$ each primer and $0.025 \mathrm{U}_{\mu} \mathrm{L}^{-1}$ Taq polymerase (Roche). PCR 148 amplifications were carried out in a TGradient thermocycler (Biometra). Aerosol resistant pipette tips 149 were used to set up all PCR reactions. Negative controls, extraction controls and distilled water were 150 included for each set of PCR amplifications. An aliquot of $1.5 \mu \mathrm{L}$ from each PCR reaction was quantified 
151 using Nanodrop 2000 spectrophotometer (Thermo Scientific), then electrophoresed on $1.75 \%$ agarose gel,

152 stained with RedSafe ${ }^{\mathrm{TM}}$ (iNtRON biotechnology) and scanned in a GelDoc XR documentation system

153 (Bio-Rad Laboratories).

154 PCR products were purified with Exo-SAP (USB, Affymetrix) and sequencing reactions were carried out 155 with an automated DNA sequencer (Applied Biosystems 3130), using the BigDyeTerminator V3.1 Cycle 156 Sequencing Kit (Applied Biosystems) with forward primers. Chromatograms were examined using

157 BioEdit Sequence Alignment Editor version 7.0.9 (Ibis Biosciences). All sequences were assessed for 158 similarity using BLAST (Basic Local Alignment Search Tool) and were submitted to GenBank 159 (Accession numbers in Table 2)

160 Identification of prey: semi nested PCR and cloning.

161 Two sets of semi-nested PCR amplifications were performed independently on the extracted DNA from

162 the digestive tract of each Octopus vulgaris paralarvae (Fig. 1). In both sets, the first PCR was carried out 163 with the universal primer 16Sar plus a reverse group specific primer (16Scrur for crustaceans/fishes and $16416 \mathrm{Scb}$ for copepods) to increase the copies of prey DNA. The second PCR was carried out using $1 \mu \mathrm{L}$ of 165 the first PCR as a template, with forward and reverse group specific primers for crustaceans/fishes and 166 copepods to amplify only prey DNA.

167 Cycling conditions for the primers $16 \mathrm{Scruf}-16 \mathrm{Scrur}$ consisted of an initial denaturation at $94^{\circ} \mathrm{C}$ for 2 min 168 followed by 33 cycles of: denaturation at $94^{\circ} \mathrm{C}$ for $30 \mathrm{~s}$, annealing at $57^{\circ} \mathrm{C}$ for $35 \mathrm{~s}$, extension at $72^{\circ} \mathrm{C}$ for $16940 \mathrm{~s}$ and a final step of $7 \mathrm{~min}$ at $72^{\circ} \mathrm{C}$. Cycling conditions for primers $16 \mathrm{Sar}-16 \mathrm{Scb}$ and subsequent $16 \mathrm{Sca}-$ $170 \quad 16 \mathrm{Scb}$ as described above.

171 All reactions were carried out in $25 \mu \mathrm{L}$, containing $50 \mathrm{ng}$ of template the first PCR and the semi nested 172 with $1 \mu \mathrm{L}$ from the product of the first PCR $2.5 \mu \mathrm{L} 10 \mathrm{X}$ PCR reaction buffer, $0.5 \mu \mathrm{L}$ dNTPs, $0.3 \mu \mathrm{L}$

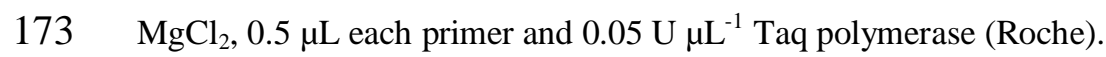

174 Semi-nested PCR products from the digestive tract of the Octopus vulgaris paralarvae obtained with 175 group specific primers (16Scruf-16Scrur) and copepod-specific primers (16Sca-16Scb) were ligated to a 176 pCR 4-TOPO plasmid vector for $15 \mathrm{~min}$ at room temperature and cloned using TOPO TA Cloning kit 177 (Invitrogen) with One Shot TOP10 chemically competent cells following the manufacturer's protocol. 178 Plasmids were extracted from 10 colonies, when possible, with the Quick Plasmid Miniprep Kit 179 (Invitrogen). Insert size was checked by PCR with universal vector specific T7 and T3 primers and 

T7.

182 Sequences recovered from clone libraries were edited and were considered to be part of the same "operational taxonomic unit" (OTU) if there was less than $1 \%$ sequence divergence, allowing for intra-

184 specific variation and Taq polymerase errors (Braley et al. 2010). OTUs were compared to sequences found in GenBank using the BLAST algorithm. A phylogenetic tree was constructed to assign unknown sequences to the highest taxonomic level and to verify the OTU identifications. The tree contained all

187 OTUs obtained from Octopus vulgaris with primers 16Scruf-16Scrur, together with the five closest 188 matches of each OTU that were downloaded from GenBank. These sequences were aligned using MAFFT v5.7 (Katoh et al. 2002) with default settings. A substitution model was selected under the

190 Akaike information criterion corrected for short sequences (AICc, Akaike 1974) as implemented in 191 jModeltest (Posada 2008). The HKY $+\gamma$ (Hasegawa et al. 1985) model was chosen to infer the 192 evolutionary history by using the Maximum Likelihood (ML) method. The analysis involved 79 193 nucleotide sequences with a total of 164 positions in the final dataset. Bootstrap probabilities with 1000

194 replications were calculated to assess reliability on each node of the ML tree. Evolutionary analyses were 195 conducted in MEGA5 (Tamura et al. 2011). If sequence similarity displayed in the BLAST was <98\%, 196 identification for the OTUs was restricted to the highest taxonomic lineage supported by bootstrap 197 probabilities higher than $70 \%$ in the consensus tree.

198 Thophic niche breadth was calculated using Czekanowski's Index (CI) with the formula:

$199 \mathrm{CI}=1-0.5 \Sigma_{\mathrm{i}}\left|\mathrm{p}_{\mathrm{i}}-\mathrm{q}_{\mathrm{i}}\right|$

200 where $p i$ is the proportion of resource item $i$ out of all items eaten by the paralarvae, and $q i$ is the 201 proportion of item $i$ in the zooplankton available to the paralarvae (Feinsinger et al. 1981). Values for CI 202 range from 1 for the broadest possible niche (a population uses resources in proportion to their 203 availability) to [min qi] for the narrowest possible niche (a population is specialized exclusively on the 204 rarest resource).

\section{Results}

207 Octopus vulgaris paralarvae and morphological analysis of the digestive tracts

208 All specimens used for morphological and genetic analysis were early hatchlings of less than 10 days according to the size (1.28-2.05 mm dorsal mantle length) and that each paralarva had 3 suckers per arm 
210 (Villanueva 1995). Visual identification of the gut contents was inconclusive, because no solid remains

211 were found. Histological sections made to the digestive tract also revealed empty digestive tracts (Fig. 2a)

212 with the exception of two stomachs which were filled with liquefied material that was impossible to 213 identify (Fig. 2b).

\section{Group specific primers and genetic database}

215 PCR tests using the designed group specific primers yielded a target band of the expected fragment size in

216 all the crustaceans and chaetognat tested. However, copepods yielded only faint bands that did not 217 correspond to copepod DNA when sequenced, so we decided to use the copepod specific primers (Braga

218 et al. 1999) in conjunction with the designed group specific primers for dietary analysis and for 219 submissions to the genetic database. No PCR products were obtained at any annealing temperature when

220 Octopus vulgaris DNA was used as template. All sequences obtained from the zooplankton collected 221 from the Ría de Vigo were submitted to GenBank (Accession numbers in Table 2).

222 Identification of preys in paralarvae by cloning

223 All octopus digestive tracts yielded amplifiable DNA when PCR was performed with the designed group

224 specific primers 16Scruf-16Scrur. Although we intended to sequence 10 colonies per larvae, some 225 samples did not yield the minimum number of colonies (Table 3). Overall, a total of 122 clones were 226 sequenced, and 115 readable sequences were obtained. All sequences corresponded to prey species, with 227114 clones corresponding to the semi-nested PCR band (16Scruf-16Scrur) and 1 clone corresponding to 228 the first PCR (16Sar-16Scruf) identified as Trachurus trachurus (OTU 19, Table 3).

229 Cloning of the amplicons obtained with copepod specific primers 16Sca-16Scb in Octopus vulgaris gut 230 contents resulted in 135 colonies, but all the sequences obtained from 125 readable clones corresponded 231 to O. vulgaris except one that amplified the DNA of Anapagurus laevis (OTU 13, Table 3).

232 Prey detected consisted of 20 different OTUs with between 1 and 5 different OTUs per paralarvae (Table 233 3). Eight OTUs were assigned to species with 78 clones displaying $100 \%$ similarity, and 1 clone 234 displaying $98 \%$ similarity to sequences from GenBank. Six OTUs showed similarities higher than 90\% 235 (13 clones), three were assigned to genus (94-95\%), two to a subfamily (Gobiinae, 93 and 92\%) and the 236 last one to a family (Goneplacidae, 90\%). The remaining four OTUs, corresponding to 22 clones, 237 displayed between $76-81 \%$ similarities and were assigned to the familial level on the basis of their 238 supported topographical position on the bootstrap consensus tree (Table 3, Fig. 3). 
$24097.4 \%$ of the clones detected and the remaining $2.6 \%$ corresponded to fishes (Table 4). Three taxa

241 accounted for 95\% of the clones; prawns (37.1\%), crabs (37.1\%) and krill (19.8\%). When considering the

242 importance of these groups in the diet of $O$. vulgaris, it is remarkable that prawns and crabs are the most

243 common prey species, detected in 14 and 12 paralarvae out of 18 respectively (Table 4). In spite of the

244 high number of krill clones, these corresponded to only three paralarvae. The rest of the taxa were

245 detected in only three paralarvae, or in just one in the case of the Thalassinidae. According to the CI the

246 trophic niche breadth is low (0.13) indicating that $O$. vulgaris paralarvae are specialist predators. All

247 OTUs were submitted to GenBank, accession numbers in Table 3.

\section{Discussion}

250 This is the first time that prey items have been identified in Octopus vulgaris paralarvae collected in the

251 wild. This was approached by using two morphological techniques; visual analysis of the digestive tracts

252 and histological sections, as well as one molecular technique using group specific primers. Although the

253 combined approach of morphological and molecular methods has been documented as a more

254 comprehensive way to understand the diet of both vertebrates and invertebrates (Casper et al. 2007;

255 Deagle et al. 2007, 2010; Braley et al. 2010), only the molecular method succeeded identifying prey in $O$.

256 vulgaris paralarvae. The small size of the paralarvae, the limitation of the oesophagus diameter, the high

257 digestion rates, and the external digestion (Nixon 1985; Parra et al. 2000; Hernández-García et al. 2000),

258 made it impossible to carry out morphological analyses of prey in O. vulgaris paralarvae during their first

259 days of life in the pelagic realm.

260 The advantage of molecular methods is that when morphological methods were ineffective, i.e. digestive

261 tract is empty or filled with unidentifiable remains, prey cells with sufficient DNA to be detected by PCR

262 are able to be recovered (King et al. 2008). The main obstacle in employing molecular techniques in small

263 animals is distinguishing prey DNA among the overall volume of host DNA (Symondson 2002). To

264 overcome this obstacle we designed group specific primers within the 16S rRNA region for crustaceans

265 and fishes, which selectively avoided amplification of Octopus vulgaris DNA. Other studies previously

266 used this region of the 16S rRNA to design group specific primers for dietary purposes (Deagle et al.

267 2005, 2007, 2009; Braley et al. 2010). Braley et al. (2010) designed a reverse group specific primer for

268 crustaceans used in conjunction with the universal 16Sar, but only 11 of 184 PCR attempts produced 
successful amplifications of krill and shrimp. In contrast, the group specific primers designed in this study

270 effectively amplified DNA, both alone and in conjunction with the universal 16Sar-16Sbr, from a wide

271 range of crustacean taxa: cladocerans, crabs, prawns, thalassinids, krill, hermit crabs, porcellanids,

272 carideans (Palaemonidae, Crangonidae and Alpheidae), mysids as well as fishes.

273 The unexpected failure to amplify copepod DNA is a potential consequence of using group specific

274 primers (Jarman et al. 2004; Deagle et al. 2005, 2007; Braley et al. 2010), which have been designed to

275 exclude from amplification Octopus vulgaris DNA. For this reason PCR had to be run with the copepod

276 specific primers 16Sca -16Scb (Braga et al. 1999) both in copepods and octopus paralarvae. These

277 primers effectively amplified copepod DNA for the genetic library (Table 2), however failed to amplify

278 copepod DNA from the digestive tract of $O$. vulgaris paralarvae. This suggests that early hatchlings of $O$.

279 vulgaris do not eat copepods, despite their presence as one of the main zooplankton taxa (table 4) and

280 being the most common prey in previous studies undertaken with other cephalopod paralarvae (Passarella

281 and Hopkins 1991; Vecchione 1991; Vidal and Haimovici 1998; Venter et al. 1999). Nonetheless, the

282 erratic movements and the extremely fast escape responses that copepods display (Yen and Fields 1992)

283 potentially pose a challenge for the early $O$. vulgaris hatchlings when compared with the predictable

284 swimming behaviour of crab and prawn zoeae or krill calyptopis. Indeed, Chen et al. (1996) found in

285 Loligo opalescens paralarvae that copepod capture is a skill acquired in an experience-dependent manner

286 during the post-hatchling stage.

287 In the current study, seven OTUs (29 clones) could not be identified to species or genus because no

288 similar sequences were present in GenBank. Phylogenetic relatedness was used to assign the unidentified

289 sequences to the highest taxonomic lineage based on the bootstrap values of the consensus tree nodes.

290 This reflects the difficulty when working with the diet of an expected generalist predator, due to the

291 limited sequence information available to target the large diversity of potential prey taxa (Blankenship

292 and Yayanos 2005; Suzuki et al. 2006, 2008). A prerequisite for resolving the diet of any predator living

293 in such a complex environment is the extensive characterization of the system (Sheppard et al. 2005; King

294 et al. 2008). In this work, five sequences that were submitted to GenBank from zooplankton species found

295 in the Ría de Vigo, were detected in the gut of the paralarvae, which highlights the importance of an

296 appropriate genetic database to obtain the highest level of identification and to reduce the uncertainty of

297 any species identification. 
298 While previous work on cephalopod paralarvae diet found that paralarvae are generalist predators, prey species detected in early hatchlings of Octopus vulgaris suggest that they are actually specialist predators

300 according to the CI obtained (0.13). Among the crustaceans, the group that primarily contribute to the 301 total abundance of zooplankton in the Ría de Vigo are krill, or Euphausiacea, which were only detected in

302 three paralarvae (Table 4). By contrast, all the paralarvae analysed ate some Decapoda, which include 303 Brachyura (crabs), Caridea (shrimps), Anomura (hermit crabs) and Thalassinidea (mud shrimps), despite 304 their much smaller contribution to the total abundance of zooplankton which was less than $4.26 \%$ (Table

305 4). In fact, the trophic selection is quite evident for carideans, which were the most abundant prey present

306 in 14 out of 18 O. vulgaris paralarvae, but whose contribution to the total zooplankton abundance was 307 only $0.28 \%$.

308 The specialist trophic strategy during the first days in the pelagic ecosystem could be a consequence of a 309 lack of skills to capture fast moving and more abundant prey, as proved in paralarvae of Loligo 310 opalescens (Chen et al. 1996). As it occurs in the former species, an ontogenic switch into a generalist 311 predation strategy would be expected as the Octopus vulgaris paralarvae grow and gain experience, but 312 further research is needed to test this hypothesis. On the other hand, if paralarvae were truly specialists 313 throughout the planktonic phase, this might explain the high mortality of $O$. vulgaris hatchlings both 314 under culture and in the wild, due to prolonged starvation periods (Vecchione 1991).

315 In conclusion, up to 20 prey species have been detected in Octopus vulgaris paralarvae obtained from the 316 wild with a PCR-based method. This is the first successful attempt to unravel the complex trophic 317 interactions that occur in the pelagic ecosystem for $O$. vulgaris paralarvae. Based on the prey species 318 detected and their relative abundances in the zooplankton, O. vulgaris paralarvae can be considered 319 specialist predators during their first days of life in the pelagic ecosystem. Such knowledge can be critical 320 to solving the primary problems associated with the integral culture of this species, which is the low 321 survival of the paralarvae likely due to inadequacy of food supplied (Iglesias et al. 2007). Further effort 322 will progress in this direction to enhance the knowledge of this species during its planktonic phase.

\section{Acknowledgements}

325 We acknowledge the comments and suggestions made by S. Jarman, B. Deagle and A. Passmore, during 326 the onset of this work. We are indebted to Adam Smolenski (University of Tasmania) and Mariana Rivas 327 (IIM, CSIC Vigo) for their valuable contribution to this research. We thank David Posada and Mateus 
Patricio (University of Vigo) for their advice to perform the phylogenetic analyses. We also thank the crew of the R/V "Mytilus" (IIM, CSIC Vigo), for their technical assistance in collecting the zooplankton

330 samples. This study was supported by the project CAIBEX (Spanish Ministry of Innovation and Science

331 CTM2007-66408-C02), LARECO (CTM2011-25929), FEDER Funds and the first author by a JAE-pre 332 grant (CSIC).

333

\section{References}

335 Akaike H (1974) A new look at the statistical model identification. IEEE Trans Automat Contr 19:716723

Altman JS, Nixon M (1970) Use of beaks and radula by Octopus vulgaris in feeding. J Zool Lond 161:2538

Andrews PLR, Tansey EM (1983) The digestive tract of Octopus vulgaris:the anatomy, physiology and pharmacology of the upper tract. J Mar Biol Assoc UK 63:109-135

Benson DA, Karsch-Mizrachi I, Lipman DJ, Ostell J, Rapp BA, Wheeler DL (2002) GenBank. Nucleic Acids Res 30:17-20

Blankenship LE, Yayanos AA (2005) Universal primers and PCR of gut contents to study marine invertebrate diets. Mol Ecol 14:891-899

Boletzky SV (2003) Biology and early life stages in cephalopod molluscs. Adv Mar Biol 44:144-202

Boucher-Rodoni R, Boucaud-Camou E, Mangold K (1987) Feeding and digestion. In: Boyle PR (ed) Cephalopod Life Cycles, vol. 2, Comparative reviews, Academic Press, London, pp 85-108

Boyle PR, Grisley MS, Robertson G (1986) Crustacea in the diet of Eledone cirrhosa (Mollusca: Cephalopoda) determined by serological methods. J Mar Biol Assoc UK 66: 867-879

Braga E, Zardoya R, Meyer A, Yen J (1999) Mitochondrial and nuclear rRNA based copepod phylogeny with emphasis on the Euchaetidae (Calanoida). Mar Biol 133:79-90

Braley M, Goldsworthy S, Page B, Steer M, Austin JJ (2010) Assessing morphological and DNA-based diet analysis techniques in a generalist predator, the arrow squid Nototodarus gouldi. Mol Eco Res $10: 466-474$

Casper R, Jarman S, Gales N, Hindell M (2007) Combining DNA and morphological analyses of faecal samples improves insight into trophic interactions: a case study using a generalist predator Mar Biol 152:815-825 
Chen DS, VanDykhuizen G, Hodge J, Gilly WF (1996) Ontogeny of copepod predation in juvenile squid (Loligo opalescens) Biol Bull 190:69-81

360 Deagle BE, Jarman SN, Pemberton D, Gales NJ (2005) Genetic screening for prey in the gut contents from a giant squid (Architeuthis sp). J Hered 96:417-423

Deagle BE, Gales NJ, Evans K, Jarman SN, Robinson S, Trebilco R, Hindell M (2007) Studying seabird diet through genetic analysis of faeces: a case study on macaroni penguins (Eudyptes chrysolophus). PLoS ONE 2, e831

Deagle BE, Kirkwood R, Jarman SN (2009) Analysis of Australian fur seal diet by pyrosequencing prey DNA in faeces. Mol Ecol 18:2022-2038

Deagle B, Chiaradia A, McInnes J, Jarman S (2010) Pyrosequencing faecal DNA to determine diet of little penguins: is what goes in what comes out? Cons Genet 11:2039-2048

Feinsinger P, Spears EE, Poole RW (1981) A simple measure of niche breadth. Ecology 62:27-12

González AF, Otero J, Guerra A, Prego R, Rocha FJ, Dale AW (2005) Distribution of common octopus and common squid paralarvae in a wind-driven upwelling area (Ría de Vigo, northwestern Spain). J Plankton Res 27:271-277

Guerra A (1978) Sobre la alimentación y el comportamiento alimentario de Octopus vulgaris. Inv Pesq $42: 351-364$

Guerra A and Nixon M (1987) Crabs and mollusc shells drilling by Octopus vulgaris (Mollusca: Cephalopoda) in the Ría de Vigo (NW Spain). J Zool 211:515-523

Hasegawa M, Kishino H, Yano T (1985) Dating the human-ape split by a molecular clock of mitochondrial DNA. J Mol Evol 22:160-174

Hernández-García V, Martín AY, Castro JJ (2000) Evidence of external digestion of crustaceans in Octopus vulgaris paralarvae. J Mar Biol Ass UK 80:559-560

Iglesias J, Fuentes L, Sánchez J, Otero JJ, Moxica C, Lago MJ (2006). First feeding of Octopus vulgaris Cuvier 1797 paralarvae using Artemia: Effect of prey size, prey density and feeding frequency. Aquaculture 261:817-822

384 Iglesias J, Sánchez FJ, Bersano JGF, Carrasco JF, Dhont J, Fuentes L, Linares F, Muñoz JL, Okumura S, Roo J, Meeren T van der, Vidal EAG, Villanueva R (2007) Rearing of Octopus vulgaris 
Itami K, Izawa Y, Maeda S, Nakai K (1963) Notes on the laboratory culture of the octopus larvae. Bull Jap Soc Sci Fish 29:514-520

Jarman S (2004) AMPLICON: Software for Designing PCR Primers on Aligned DNA Sequences. Bioinformatics 20:1644-1645

391 Jarman S, Deagle B, Gales NJ (2004) Group specific polymerase chain reaction for DNA-based analysis of species diversity and identity in dietary samples. Mol Ecol 13:1313-1322

393 Katoh K, Misawa K, Kuma K, Miyata T (2002) MAFFT: a novel method for rapid multiple sequence alignment based on fast Fourier transform. Nucleic Acids Res 30:3059-3066

King RA, Read DS, Traugott M, Symondson WOC (2008) Molecular analysis of predation: a review of best practice for best DNA-based approaches. Mol Ecol 17:947-963

Mather JA (1991) Foraging, feeding and prey remains in middens of juvenile Octopus vulgaris (Mollusca: Cephalopoda). J Zool Lond 224:27-39

Nigmatullin CM, Ostapenko AA (1976) Feeding of Octopus vulgaris Lam. from the northwest Africa coast. ICES CM 1-15

Nixon M (1984) Is there external digestion by Octopus? J Zool Lond 202:441-447.

Nixon M (1985) Capture of prey, diet and feeding of Sepia officinalis and Octopus vulgaris (Mollusca: Cephalopoda) from hatchling to adult. Vie Milieu 35:255-261

Nixon M (1987) Cephalopods diet. In: Boyle PR (ed) Cephalopod Life Cycles, vol. 2, Comparative reviews, Academic Press, London, pp 201-219

Otero J, Álvarez-Salgado XA, González AF, Gilcoto M, Guerra A (2009) Influence of high-frequency coastal upwelling events on Octopus vulgaris larval dynamics in the NW Iberian shelf. Mar Ecol Prog Ser 386:123-132

Parra G, Villanueva R, Yufera M (2000) Respiration rates in late eggs and early hatchlings of the common octopus, Octopus vulgaris. J Mar Biol Ass UK 80:557-558

Passarella KC and Hopkins TL (1991) Species composition and food habits of the micronektonic cephalopod assemblage in the eastern Gulf of Mexico. Bull Mar Sci 49:638-659

414 Rasero M, González AF, Castro BG, Guerra A (1996) Predatory relationships of two sympatric 
418 Roura A, González AF, Pascual S, Guerra A (2010) A molecular approach to identifying the prey of cephalopod paralarvae. ICES J Mar Sci 67:1408-1412

Sheppard SK, Harwood JD (2005) Advances in molecular ecology: tracking trophic links through predator-prey foodwebs. Funct Ecol 19:751-762

Simon C, Frati F, Beckenbach A, Crespi B, Liu H, Flook P (1994) Evolution, weighting, and phylogenetic utility of mitochondrial gene sequences and a compilation of conserved polymerase chain reaction primers. Ann Entomol Soc Am 87:651-701

Smale MJ, Buchan PR (1981) Biology of Octopus vulgaris off the east coast of South Africa. Mar Biol 65:1-12

Suzuki N, Murakami K, Takeyama H, Chow S (2006) Molecular attempt to identify prey organisms of lobster phyllosoma larvae. Fish Sci 72:342-349

Suzuki N, Hoshino K, Murakami K, Takeyama H, Chow S (2008) Molecular diet analysis of phyllosoma larvae of the japanese spiny lobster Panulirus japonicus (Decapoda: Crustacea). Mar Biotech $10: 49-55$

Sweeney MJ, Roper CFE, Mangold K, Clarke MR, Boletzky SV (1992) 'Larval' and juvenile cephalopods: a manual for their identification. Smithsonian Contributions to Zoology

Symondson W (2002) Molecular identification of prey in predator diets. Mol Ecol 11:627-641

Tamura K, Peterson D, Peterson N, Stecher G, Nei M, and Kumar S (2011) MEGA5: Molecular evolutionary genetics analysis using maximum likelihood, evolutionary distance, and maximum parsimony methods. Mol Biol Evol 28:2731-2739

Vecchione M (1991) A method for examining the structure and contents of the digestive tract in paralarvae squids. Bull Mar Sci 49:300-308

Venter JD, Wyngaardt Sv, Verschoor JA (1999) Detection of zooplankton prey in squid paralarvae with Inmunoassay. J Inmunoassay 20:127-149

Vidal EAG, Haimovici M (1998) Feeding and the possible role of the proboscis and mucus cover in the ingestion of microorganisms by rhynchoteuthion paralarvae (Cephalopoda: Ommastrephidae). Bull Mar Sci 63:305-316

Villanueva R (1995) Experimental rearing and growth of planktonic Octopus vulgaris from hatching to settlement. Can J Fish Aquat Sci 52:2639-2650 
447 Villanueva R, Norman M (2008) Biology of the planktonic stages of benthic octopuses. Oceanogr Mar $448 \quad$ Biol Annu Rev 46:105-202

449 Yen J, Fields DM (1992) Escape responses of Acartia hudsonica (Copepoda) nauplii from the flow field 450 of Temora longicornis (Copepoda). Arch Hydrobiol Beih 36:123-134

451 
453 Fig.1 Diagram of the two semi nested PCR undertaken on each paralarvae, showing the prey targeted and 454 the primers used on each PCR

455

456 Fig.2 Histological sections of Octopus vulgaris paralarvae stained with haematoxylin-eosin showing (a) 457 an empty stomach and (b) a stomach filled with undefined material $\left(^{*}\right)$ impossible to recognise. 458 Abbreviations, br: brain; di gl: digestive gland; oe: oesophagus; ra: radula; st: stomach; su: sucker. Scale 459 bars $100 \mathrm{~nm}$.

460

461 Fig.3 Maximum Likelihood tree for affiliating 18 operational taxonomic units (OTUs) obtained from the 462 digestive tract Octopus vulgaris paralarvae. OTUs obtained from the digestive tract are shown in bold.

463 Eukaryote rRNA sequences obtained by the BLAST searches are in italics with accession numbers. Only 464 bootstrap probabilities higher than 60 after 1000 replications are shown in the branches 


\section{Octopus vulgaris digestive tract DNA}

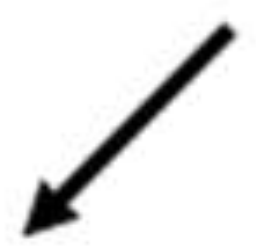

Crustaceans and fishes

16 Sar

16Scrur

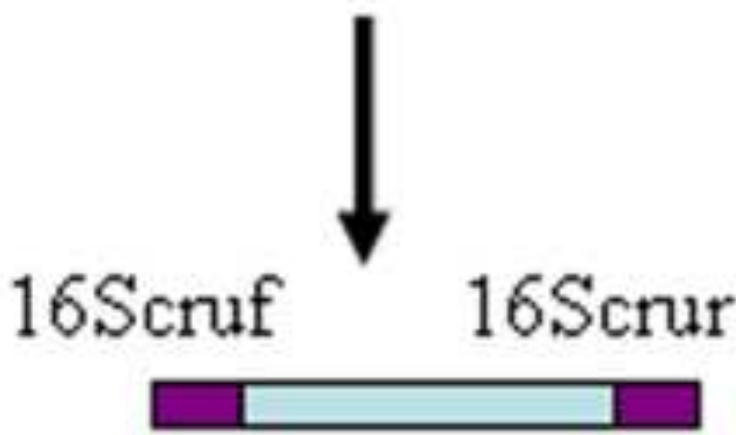

Copepods

16 Sar

$16 \mathrm{Scb}$

16 Sca

$16 \mathrm{Scb}$

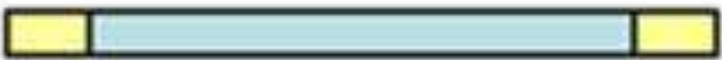



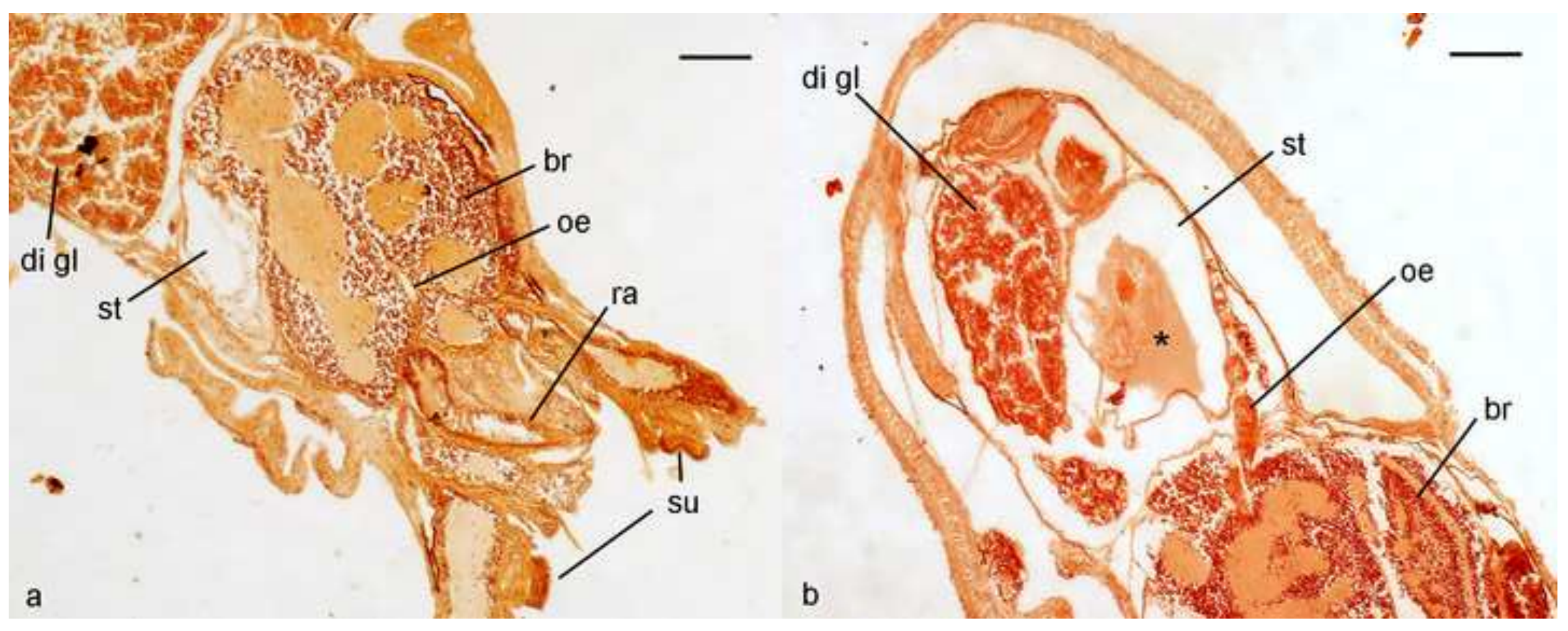


\section{Figure 3}

Click here to download high resolution image

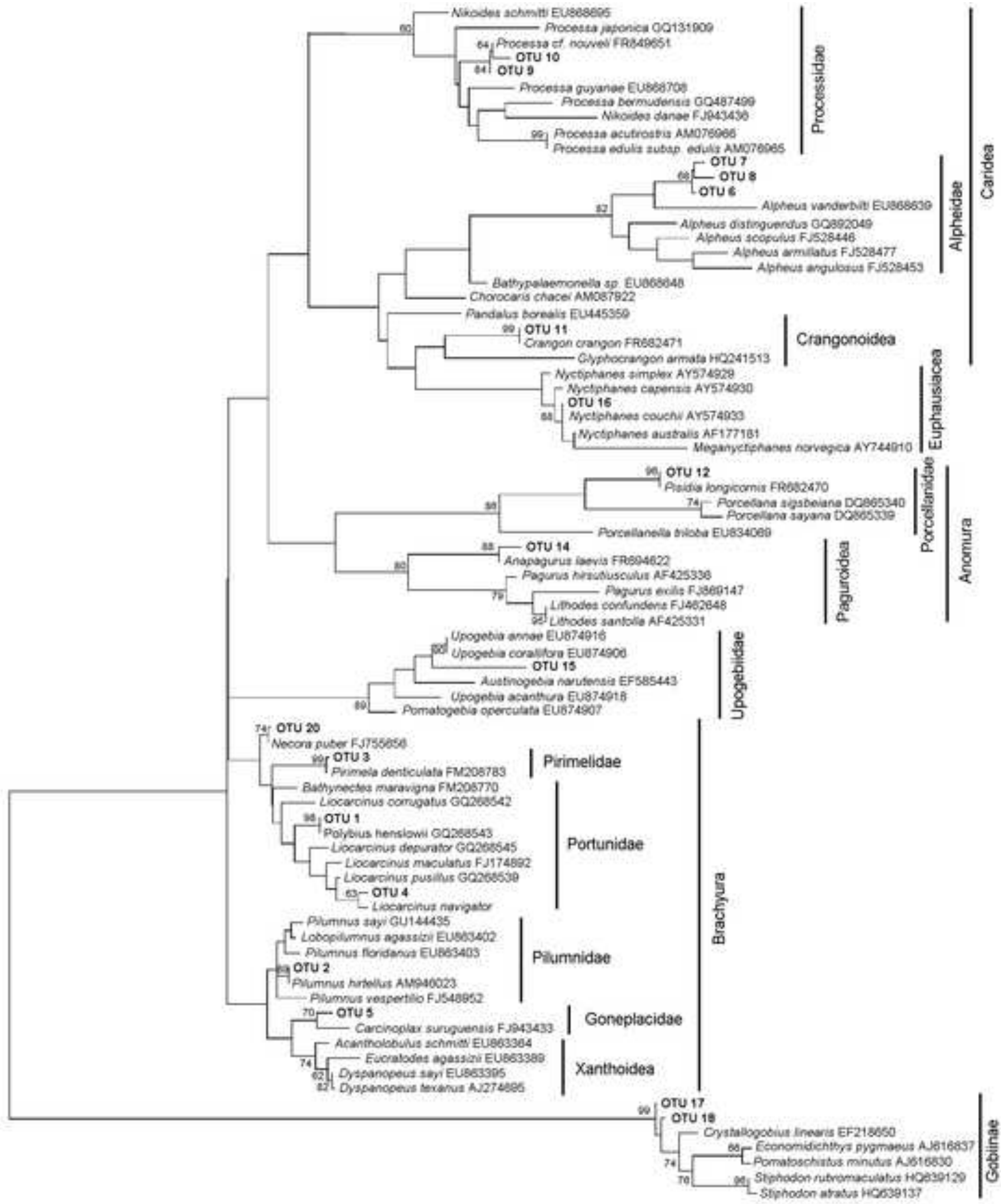


Table 1. Primers used in the current study showing the sequence of forward and reverse primers, the annealing temperature of each primer and the sizes of the amplified PCR products.

\begin{tabular}{|c|c|c|c|c|}
\hline $\begin{array}{l}\text { Target } \\
\text { taxon }\end{array}$ & Forward primer $\left(5^{\prime}-3^{\prime}\right)$ & Reverse primer $\left(5^{\prime}-3^{\prime}\right)$ & $\begin{array}{l}\text { Annealing } \\
\text { Temperature }\end{array}$ & $\begin{array}{l}\text { Product } \\
\text { size (bp) }\end{array}$ \\
\hline Universal & $\begin{array}{c}\text { 16Sar } \\
\text { CGCCTGTTTATCAAAAACAT }\end{array}$ & $\begin{array}{c}16 \mathrm{Sbr} \\
\text { CCGGTCTGAACTCAGATCACGT }\end{array}$ & $50^{\circ} \mathrm{C}$ & $550-620$ \\
\hline Eucarida & $\begin{array}{c}\text { 16Scruf } \\
\text { GACGATAAGACCCTATAA }\end{array}$ & $\begin{array}{c}\text { 16Scrur } \\
\text { CGCTGTTATCCCTAAAGTAA }\end{array}$ & $57^{\circ} \mathrm{C}$ & 194-204 \\
\hline Copepod & $\begin{array}{c}\text { 16Sca } \\
\text { TGTTAAGGTAGCATAGTAAT }\end{array}$ & $\begin{array}{c}16 \mathrm{Scb} \\
\text { ATTCAACATCGAGGTCACAA }\end{array}$ & $50^{\circ} \mathrm{C}$ & $356-387$ \\
\hline
\end{tabular}


Table 2. List of species sequenced to create a 16S rRNA library of zooplankton present in the Ría de Vigo including GenBank Accession numbers, size of PCR amplicons in base pairs and PCR primers used to amplify each species.

\begin{tabular}{|c|c|c|c|c|c|}
\hline $\begin{array}{c}\text { Accession } \\
\text { number }\end{array}$ & Species & Taxon & $\begin{array}{l}\text { Length } \\
\text { (bp) }\end{array}$ & Primer set & $\begin{array}{c}\text { Homology } \\
(\%)\end{array}$ \\
\hline FR851238 & Jaxea nocturna & Thalassinidae & 361 & 16Sar-16Scrur & 99 \\
\hline FR851240 & Callianasa subterranea & Thalassinidae & 365 & 16Sar-16Scrur & 99 \\
\hline FR851239 & Podon intermedius & Cladocera & 357 & 16Sar-16Scrur & 99 \\
\hline FR682469 & Nyctiphanes couchii & Euphausiacea & 356 & 16Sar-16Scrur & 99 \\
\hline FR849634 & Galathea strigosa & Galatheidae & 338 & 16Sar-16Scrur & \\
\hline FR682470 & Pisidia longicornis & Porcellanidae & 380 & 16Sar-16Scrur & \\
\hline FR849633 & Solenocera membranacea & Penaeidae & 367 & 16Sar-16Scrur & \\
\hline FR682471 & Crangon crangon & Crangonidae & 371 & 16Sar-16Scrur & \\
\hline FR694622 & Anapagurus laevis & Paguridae & 363 & 16Sar-16Scrur & \\
\hline FR849637 & Cestopagurus timidus & Paguridae & 276 & 16Scruf-16Sbr & \\
\hline FR849651 & Processa cf. nouveli & Processidae & 170 & 16scruf-16Scrur & \\
\hline FR849636 & Leptomysis gracilis & Mysidacea & 198 & $16 S c r u f-16 S b r$ & \\
\hline FR849648 & Calanus helgolandicus & Copepoda & 349 & $16 S c a-16 S c b$ & 99 \\
\hline FR849642 & Calanoides carinatus & Copepoda & 346 & $16 S c a-16 S c b$ & \\
\hline FR849638 & Mesocalanus tenuicornis & Copepoda & 341 & $16 S c a-16 S c b$ & \\
\hline FR849639 & Paraeuchaeta hebes & Copepoda & 340 & $16 S c a-16 S c b$ & \\
\hline FR849643 & Paracalanus parvus & Copepoda & 365 & $16 S c a-16 S c b$ & \\
\hline FR849645 & Pseudocalanus elongatus & Copepoda & 275 & $16 S c a-16 S c b$ & \\
\hline FR849646 & Metridia lucens & Copepoda & 372 & $16 S c a-16 S c b$ & 99 \\
\hline FR849641 & Pleuromamma gracilis & Copepoda & 329 & $16 S c a-16 S c b$ & \\
\hline FR849650 & Diaixis pygmaea & Copepoda & 206 & $16 S a r-16 S c b$ & \\
\hline FR849649 & Acartia clausii & Copepoda & 323 & $16 S c a-16 S c b$ & 96 \\
\hline FR849634 & Clausocalanus sp. & Copepoda & 284 & $16 S c a-16 S c b$ & \\
\hline FR849640 & Oithona sp. & Copepoda & 397 & $16 S c a-16 S c b$ & \\
\hline FR849647 & Candacia armata & Copepoda & 350 & $16 S c a-16 S c b$ & \\
\hline
\end{tabular}


Table 3. Prey DNA (OTUs 1-20) detected in the eighteen Octopus vulgaris paralarvae (Oc1 to Oc18) by cloning the PCR products obtained with group specific primers (16Scruf-16Scrur), including closest matches, their GenBank Accession numbers and percentages of similarity obtained from BLAST.

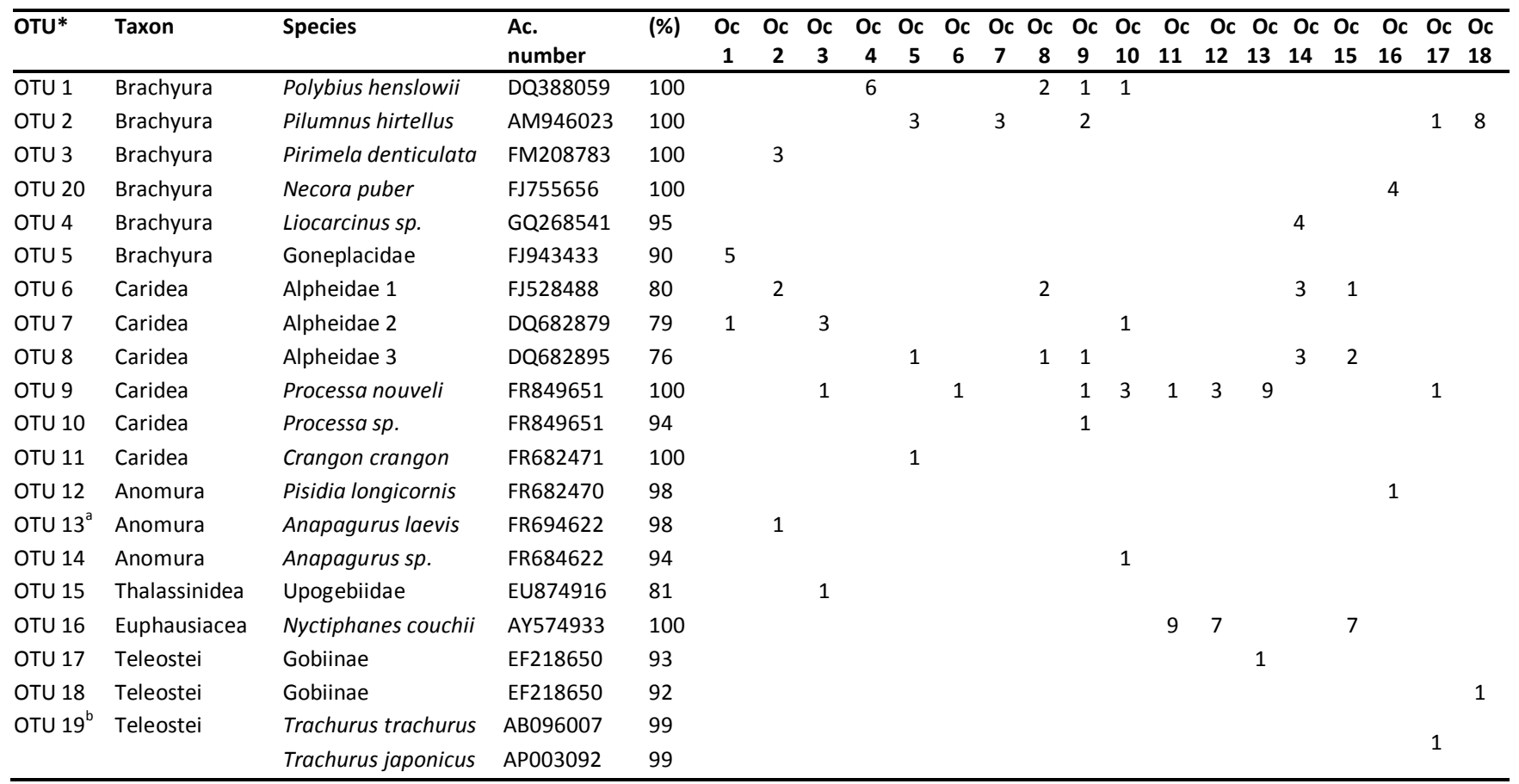

*Each Operational Taxonomic Unit (OTU) has been submitted to GenBank, accession numbers: FR849614-849632 and HE586322. ${ }^{\mathrm{a}}$ Obtained with primers $16 \mathrm{Sca}-16 \mathrm{Scb} .{ }^{\mathrm{b}}$ Obtained with primers $16 \mathrm{Sar}-16 \mathrm{Scrur}$ 
Table 4. Composition of the zooplankton community during the study expressed as the percentage of each taxon to the total abundance and the diet in Octopus vulgaris paralarvae by the number and percentage of clones corresponding to a given taxon and the number of paralarvae where those taxa were detected.

\begin{tabular}{llccc}
\hline Phyla & Taxon & $\begin{array}{c}\text { Wild } \\
\text { Zooplankton } \\
\text { Abundance }(\%)\end{array}$ & $\begin{array}{c}\text { Clones } \\
\text { detected and } \\
\text { percentage (\%) }\end{array}$ & $\begin{array}{c}\text { Number of } \\
\text { paralarvae }\end{array}$ \\
\hline Crustacea & Euphausiacea & 27.8765 & $23(19.8)$ & 3 \\
Echinodermata & Ofiuroidea & 20.3526 & & \\
Crustacea & Copepoda & 19.0708 & & \\
Chordata & Thaliacea & 15.2601 & & \\
Crustacea & Cirripeda & 3.9272 & & \\
Chaetognatha & Sagittidae & 2.7184 & & \\
Crustacea & Cladocera & 2.2304 & & \\
Crustacea & Anomura & 2.1644 & $3(2.6)$ & \\
Crustacea & Brachyura & 1.8174 & $43(37.1)$ & \\
Cnidaria & Cnidaria & 1.5349 & & \\
Echinodermata & Equinoidea & 1.2949 & & \\
Mollusca & Gastropoda & 0.8575 & & \\
Crustacea & Caridea & 0.2777 & $43(37.1)$ & \\
Chordata & Teleostei & 0.2518 & $3(2.6)$ & \\
Crustacea & Misidacea & 0.2352 & & \\
Crustacea & Amphipoda & 0.0297 & & \\
Platemintha & Turbellaria & 0.0215 & & \\
Annelida & Polychaeta & 0.0203 & & \\
Mollusca & Bivalvia & 0.0144 & & \\
Briozoa & Ciphonaute & 0.0126 & & \\
Crustacea & Cumacea & 0.0088 & & \\
Crustacea & Thalassinoidea & 0.0084 & $1(0.9)$ & \\
Crustacea & Stomatopoda & 0.0068 & & \\
Crustacea & Dendrobranchiata & 0.0030 & & \\
Crustacea & Isopoda & 0.0018 & & \\
Mollusca & Cephalopoda & 0.0016 & & \\
Cephalochordata & Branchiostomidae & 0.0009 & & \\
Crustacea & Ostracoda & 0.0007 & & \\
\hline & & & & \\
\end{tabular}


Table 5
Click here to download Supplementary Material: Roura Table 5.doc Click here to download Supplementary Material: Roura Table 5. doc $\left(\frac{10}{2}\right.$ (1) (1) (1) (1)

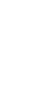
(1) (1)

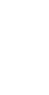
(1) (1) (1)

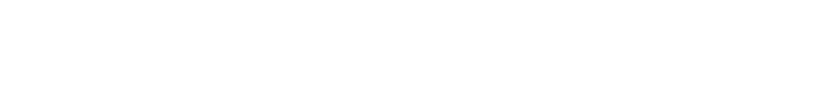

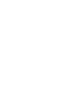
(1) (1)

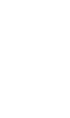
(1) (1)

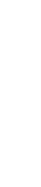

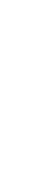
. . . 列 . .

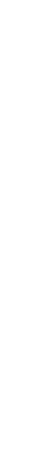
列

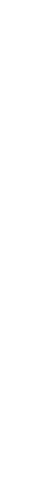

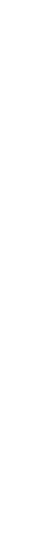

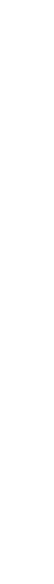
. 